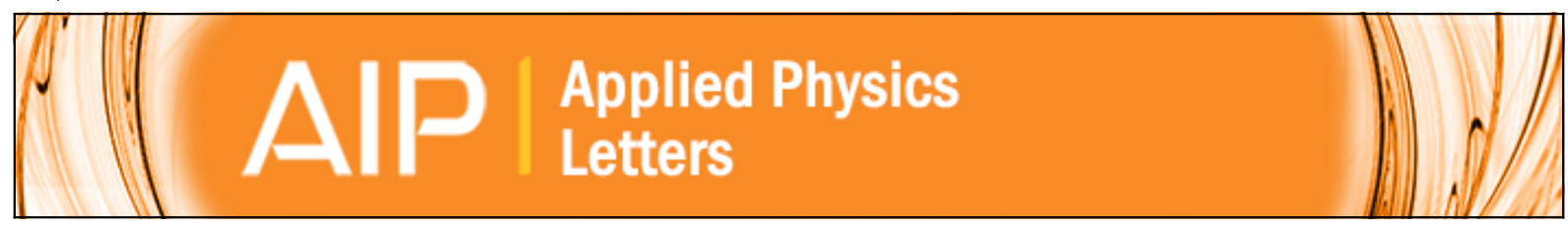

\title{
Plasma-assisted pulsed laser deposition of SrBi 2 Ta 209 thin films of improved ferroelectric and crystalline properties
}
A. C. Rastogi, S. Tirumala, and S. B. Desu

Citation: Applied Physics Letters 74, 3492 (1999); doi: 10.1063/1.124140

View online: http://dx.doi.org/10.1063/1.124140

View Table of Contents: http://scitation.aip.org/content/aip/journal/apl/74/23?ver=pdfcov

Published by the AIP Publishing

\section{Articles you may be interested in}

Properties of $\mathrm{Sr} \mathrm{Bi} 2 \mathrm{Ta} 0.8 \mathrm{Nb} 1.2 \mathrm{O} 9$ thin films deposited by plasma-assisted pulsed-laser deposition

J. Vac. Sci. Technol. A 25, 148 (2007); 10.1116/1.2404687

Ferroelectric properties of laser-ablated $\mathrm{Sr} 1 \times \mathrm{A} \times \mathrm{Bi} 2 \mathrm{Ta} 2 \mathrm{O} 9$ thin films (where $\mathrm{A}=\mathrm{Ba}, \mathrm{Ca}$ )

Appl. Phys. Lett. 80, 637 (2002); 10.1063/1.1436528

CaBi 2 Ta 209 ferroelectric thin films prepared by pulsed laser deposition

Appl. Phys. Lett. 78, 2925 (2001); 10.1063/1.1370545

Epitaxial growth of (001)-oriented and (110)-oriented SrBi 2 Ta 209 thin films

Appl. Phys. Lett. 73, 2923 (1998); 10.1063/1.122631

Microstructure-dependent ferroelectric properties of SrBi 2 Ta 209 thin films fabricated by radio frequency magnetron sputtering

J. Vac. Sci. Technol. A 16, 1258 (1998); 10.1116/1.581270

\section{AlP Re-register for Table of Content Alerts}

\section{Create a profile. \\ Sign up today!}

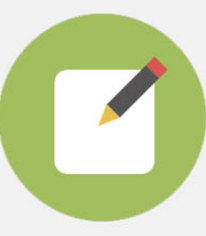




\title{
Plasma-assisted pulsed laser deposition of $\mathrm{SrBi}_{2} \mathrm{Ta}_{2} \mathrm{O}_{9}$ thin films of improved ferroelectric and crystalline properties
}

\author{
A. C. Rastogi, ${ }^{\text {a) }}$ S. Tirumala, and S. B. Desu \\ Department of Materials Science and Engineering, Virginia Polytechnic Institute \& State University, \\ Blacksburg, Virginia 24061
}

(Received 12 November 1998; accepted for publication 9 April 1999)

\begin{abstract}
Significant effect of the introduction of $\mathrm{O}_{2}$-plasma discharge during pulsed laser ablative deposition of $\mathrm{SrBi}_{2} \mathrm{Ta}_{2} \mathrm{O}_{9}$ (SBT) films on improving the crystallite orientation and ferroelectric properties has been described. $\mathrm{O}_{2}$-plasma assists in the formation of highly crystalline films at a low $700{ }^{\circ} \mathrm{C}$ temperature over (111) oriented Pt films coated $\mathrm{Si}(100)$ single crystal substrates at a nominal pressure of 200 mTorr. Plasma excitation potential, applied at an auxiliary ring electrode placed near the substrate, has a profound effect on surface morphology, crystallite orientation, and remnant polarization, $P_{r}$ values. At $-350 \mathrm{~V}$, SBT growth at $700{ }^{\circ} \mathrm{C}$ with predominant $(a-b)$ orientation showing high $P_{r} \sim 6.5 \mu \mathrm{C} / \mathrm{cm}^{2}$ in the as-deposited state has been obtained. In comparison, SBT films deposited identically but without the plasma show a low $P_{r}$ of $\sim 1.7 \mu \mathrm{C} / \mathrm{cm}^{2}$. Ionized cationic species along with ionic and atomic oxygen present in the plasma improve thermodynamic stability of the film growth through enhanced chemical reactivity and thus eliminates the need for any severe postgrowth crystallization anneal step in the synthesis of SBT films. Impingement of energetic $\mathrm{O}_{2}$ ions and atomic oxygen helps lower the nucleation barrier for the growth of $(a-b)$ crystallites and changes the $c$-axis orientation from normal to near parallel to the film plane. Quality of the film declines with the plasma excitation potential as enhanced kinetic energy of impinging $\mathrm{O}_{2}$ ions introduce defects and reduce nucleation density by resputtering from the substrate. (C) 1999 American Institute of Physics. [S0003-6951(99)00423-4]
\end{abstract}

Among the new ferroelectric oxide materials being investigated for application in nonvolatile random access memory (NvRAM) devices, bilayered perovskites appear more promising. ${ }^{1-4}$ Recent studies ${ }^{5-7}$ have shown that thin films of strontium bismuth tantalate (SBT), $\mathrm{SrBi}_{2} \mathrm{Ta}_{2} \mathrm{O}_{9}$ and its solid solutions with $\mathrm{Bi}_{3} \mathrm{Ti}\left(\mathrm{Ta}_{1-y} \mathrm{Nb}_{y}\right) \mathrm{O}_{9}$ and $\mathrm{Bi}_{3} \mathrm{Ta}_{1-y} \mathrm{Nb}_{y} \mathrm{O}_{9}$ exhibit excellent retention characteristics, low leakage currents, and almost polarization fatigue free operation for up to $10^{12}$ switching cycles on $\mathrm{Pt}$ electrodes. SBT films have been deposited by a number of vapor phase techniques, such as, metal organic chemical vapor deposition $^{8}$ (MOCVD), radio frequency (rf) sputtering ${ }^{9}$ and laser ablation, ${ }^{2,10-13}$ and solution phase techniques such as sol-gel $^{14}$ and metal organic solution deposition $6,15,16$ (MOSD). A major thrust of these deposition techniques is to overcome two key issues involved in the application of SBT thin films in high density (4 Mb) RAMs, namely the lower values of remnant polarization and high temperature $\left(800^{\circ} \mathrm{C}\right)$ processing/crystallization steps involved in the film synthesis. High temperature film processing is required to eliminate pyrochlore phase formation, improve microstructure, and attain a critical grain size. ${ }^{13}$ Due to highly anisotropic nature of the ferroelectric properties on the crystal structure in bilayered perovskites, orientation of the crystallites in the SBT films is also relevant for attaining high $P_{r}$ and low $E_{c}$ values. Ferroelectric behavior of SBT is due to spontaneous polarization from $\mathrm{Sr}-\mathrm{Ta}-\mathrm{O}$ perovskite lattice units stacked alternatively between $\left(\mathrm{Bi}_{2} \mathrm{O}_{2}\right)^{2+}$ layers in a pseudotetragonal structure. ${ }^{17}$ Since the dipole interaction between the perovskite blocks is prevented by nonferroelectric $\left(\mathrm{Bi}_{2} \mathrm{O}_{2}\right)^{2+}$

\footnotetext{
${ }^{a)}$ Permanent address: Division of Electronic Materials, National Physical Laboratory, New Delhi 110 012, India.
}

planes, very little polarization exists along the $c$ axis which is perpendicular to the $\left(\mathrm{Bi}_{2} \mathrm{O}_{2}\right)^{2+}$ planes. Thus, as the spontaneous polarization resides along the $(a-b)$ plane, growth of SBT films in this crystal orientation is essential for practical devices.

In chemical techniques, off stoichiometric Sr-deficient SBT films, ${ }^{16}$ texture control by buffer layers, ${ }^{18}$ postgrowth crystallization at low oxygen partial pressures, ${ }^{19}$ and by rapid thermal annealing ${ }^{14}$ are the important process variables employed. In vapor phase techniques, pulsed laser ablation, which is the most successful technique for SBT film growth, variations in the $\mathrm{Sr} / \mathrm{Bi}$ ratio, ${ }^{10}$ oxygen pressure, ${ }^{12}$ and substrate temperature ${ }^{13}$ have been attempted. In this work, we have carried out PLD growth of SBT films in the presence of oxygen plasma containing energetic $\mathrm{O}_{2}$ ions. We demonstrate plasma parameters, especially the excitation potential as an approach to form highly $(a-b)$ oriented SBT films at a lower, $700{ }^{\circ} \mathrm{C}$ temperature. Under the plasma conditions employed in this experiment, the $\mathrm{O}_{2}$ ions cause enhancement of the reactivity of component oxides and the modification in the film nucleation and growth kinetics. This has a profound effect on the SBT film microstructure and crystal orientation resulting in the improvement in ferroelectric properties and elimination of any severe postgrowth crystallization step.

In the present pulsed laser deposition (PLD) system, $\mathrm{O}_{2}$ plasma is excited by applying a high dc potential to a ring electrode placed coplanar with the substrate at a distance of $10 \mathrm{~mm}$ between the target and substrate heater/holder (Fig. 1). A dc potential of $300-700 \mathrm{~V}$ of either polarity can be applied to the auxiliary ring electrode with respect to the target which is kept electrically grounded to create the glow discharge under typical oxygen partial pressures of 80 to 400 mTorr in the PLD chamber. The target was a 25-mm-diam 


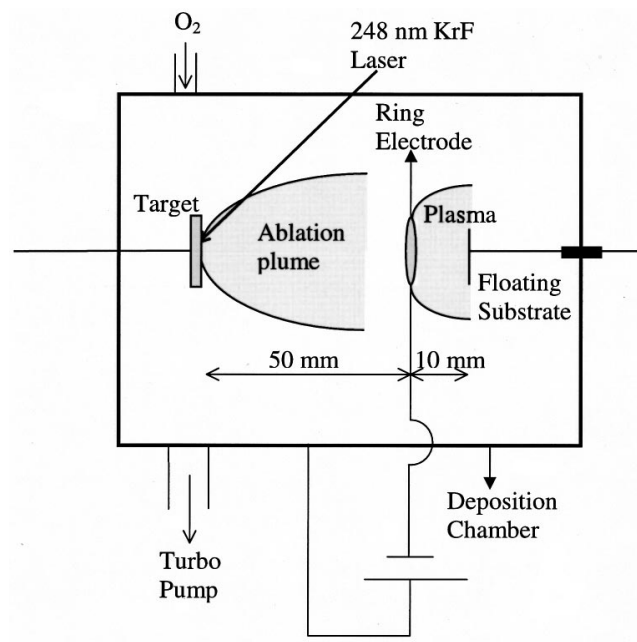

FIG. 1. Schematic diagram of plasma-assisted pulsed laser deposition technique.

disk of stoichiometric $\mathrm{SrBi}_{2} \mathrm{Ta}_{2} \mathrm{O}_{9}$ prepared by the conventional ceramic route. The rotating target was irradiated by excimer laser (Lambda Physik LPX300) utilizing $248 \mathrm{~nm}$ $\mathrm{KrF}$ radiations operating at $10 \mathrm{~Hz}$ and an energy density of $1.5 \mathrm{~J} \mathrm{~cm}^{-2}$. The usual distance between the target and substrate was $60 \mathrm{~mm}$. In this study, the SBT films were deposited over a (111) oriented Pt film (1800 A) coated $\mathrm{TiO}_{2} \mathrm{SiO}_{2} / \mathrm{Si}(100)$ single crystal substrates at $700^{\circ} \mathrm{C}$ under an oxygen pressure of $200 \mathrm{mTorr}$ in the presence of plasma excited by application of negative 350,450 , and $700 \mathrm{~V}$ to the auxiliary electrode. Some films were subjected to a postgrowth oxygen annealing for periods ranging from 30 to 90 min, especially when a comparison was required with SBT films grown without the plasma assistance which needed to be optimized for ferroelectric properties. It was necessary for all films to be annealed for $10-20 \mathrm{~min}$ at $750^{\circ} \mathrm{C}$ with a top Pt electrode to improve the contact and enable recording of the polarization hysteresis. Ferroelectric properties were measured by RT66A tester under virtual ground conditions. For this, an array of Pt contacts, each of nominal area 3 $\times 10^{-4} \mathrm{~cm}^{2}$ were sputter deposited using an appropriate shadow mask.

As-deposited SBT films formed without plasma did not show a ferroelectric behavior initially. It was necessary to subject them to a postdeposition crystallization annealing step at the deposition temperature for over $60 \mathrm{~min}$ in the presence of flowing oxygen and an additional $20 \mathrm{~min}$ after the top Pt contact has been deposited. $P_{r}$ values for conventionally coated SBT films are still poor $\sim 1.7 \mu \mathrm{C} / \mathrm{cm}^{2}$. Remnant polarization values vastly improve for films grown in the presence of plasma. We observed a dramatic improvement in the ferroelectric properties for SBT films deposited at a plasma potential of $-350 \mathrm{~V}$. First, it was not required for these SBT films to be subjected to any postdeposition crystallization anneal and second, the $P_{r}$ values were substantially high. Figure 2 shows the comparison of the $P-E$ curves. Thickness of these films was 0.15 (without plasma) and $0.16 \mu \mathrm{m}$ (with plasma). The remnant polarization of 1.2 and $6.6 \mu \mathrm{C} / \mathrm{cm}^{2}$ and coercive field values of 40 and 51 $\mathrm{KV} / \mathrm{cm}$ were observed in the two cases, respectively. Clearly, the presence of $\mathrm{O}_{2}$ plasma assists in the growth of SBT films displaying much improved ferroelectric proper-

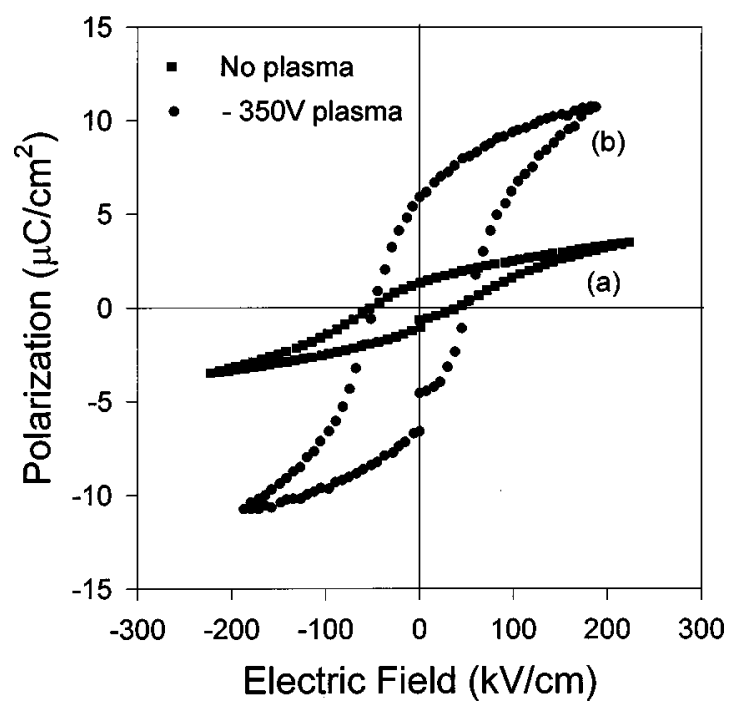

FIG. 2. Polarization hysteresis loop for PLD grown $\mathrm{SrBi}_{2} \mathrm{Ta}_{2} \mathrm{O}_{9}$ thin films in the as-deposited state not subjected to any postdeposition annealing step. Curve (a) formed without plasma and curve (b) formed with $\mathrm{O}_{2}$ plasma using a $-350 \mathrm{~V}$ excitation potential.

ties. The plasma excitation potential constitutes an important process variable in this regard. Earlier studies ${ }^{10,11}$ on pulsed laser deposited SBT films have found that postdeposition annealing at $800^{\circ} \mathrm{C}$ is an inevitable process step in order to form a fully crystallized SBT phase and increase the remnant polarization values to $\sim 4.0 \mu \mathrm{C} / \mathrm{cm}^{2}$. SBT films deposited at $700^{\circ} \mathrm{C}$ with the assistance of $\mathrm{O}_{2}$ plasma have a dominant growth of crystallites where the $(a-b)$ plane lies along the film plane. This is evident from the x-ray diffraction patterns of the as-deposited SBT films formed with and without plasma and not subjected to any postgrowth anneal as shown in Fig. 3. All films are well crystallized. Film deposited without the plasma exhibit mainly the $(00 l)$ diffraction peaks along with a (115) peak implying a preferred orientation of $c$-axis perpendicular to the film plane. A dominant number of crystallites grow with the $c$ planes lying along the film surface. Films with $c$-axis oriented crystallites, due to extremely low polarization values are unsuitable for application in memory devices. However, laser ablative deposition of SBT films, if carried out in the presence of plasma, but otherwise under conditions identical to those used for SBT film growth without the plasma, pronounced effect on crystallite orientation is observed. At a $-700 \mathrm{~V}$ excitation potential, $(00 l)$ diffraction peaks have either diminished in intensity or disappeared. In the diffraction pattern, the peaks corresponding to (008) and (00 14) planes are no longer seen and only (006) is observed. At a still lower plasma excitation potential of $-350 \mathrm{~V}$, there are multiple peaks belonging to $(h k 0)$ or $(h 0 l)$, but none from $(00 l)$ planes. The (115) peak present in both sets of SBT films is the main peak corresponding to perovskite phase. The full width at half maximum (FWHM) of (115) peak for a $(00 l)$ oriented SBT film formed without plasma is $0.68^{\circ}$. It decreases for films deposited in the presence of plasma to $0.60^{\circ}$ for $-700 \mathrm{~V}$ and remarkably to $0.35^{\circ}$ for $-350 \mathrm{~V}$ plasma excitation potentials indicating a growth of large $(a-b)$ oriented crystallites in SBT films deposited with plasma assistance. The intensity ratios $I \Sigma(00 l) / I \Sigma(h k l)$ decreases from a high value of 1.53 in the 


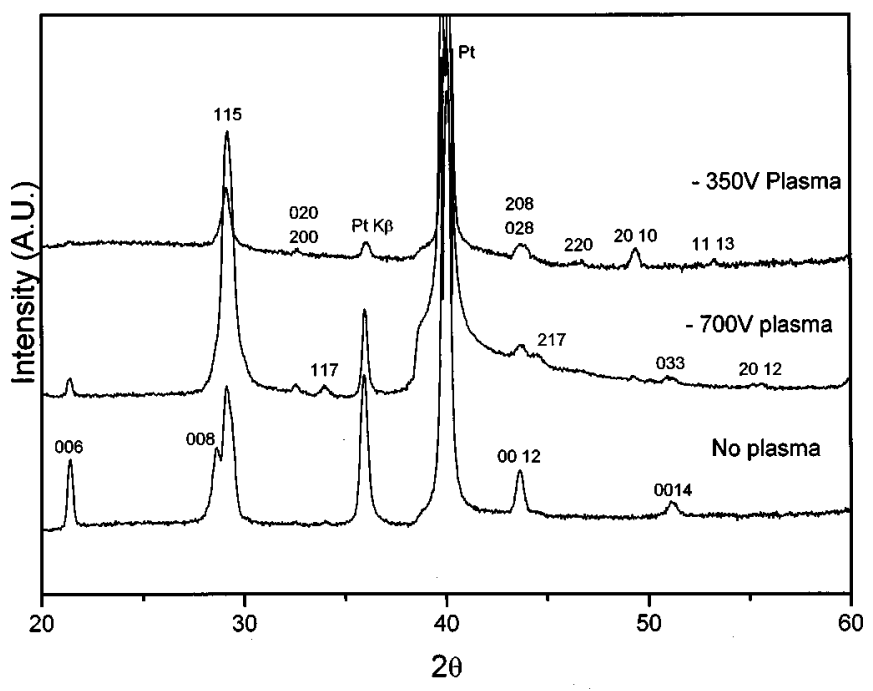

FIG. 3. X-ray diffraction patterns of PLD grown $\mathrm{SrBi}_{2} \mathrm{Ta}_{2} \mathrm{O}_{9}$ thin films in the as-deposited state formed without $\mathrm{O}_{2}$ plasma and with $\mathrm{O}_{2}$ plasma using the excitation potentials of -700 and $-350 \mathrm{~V}$.

case of films formed without the plasma to 1.22 and 0 for SBT formed in $\mathrm{O}_{2}$ plasma at -700 and $-350 \mathrm{~V}$, respectively. It is thus inferred that pulsed laser deposition of SBT film in the presence of $\mathrm{O}_{2}$ plasma has a strong effect on the crystallite orientation, with lower plasma potentials enhancing the growth of $(a-b)$ planes. The preferred $c$-axis orientation normal to the film plane in films formed without the plasma, progressively changes the orientation with plasma potential to a preferred $c$-axis direction nearly inclined along the film plane at lower potentials. With the assumption that SBT film crystallizes in pseudotetragonal structure, lattice constants were determined from (115), (208), and (006) reflections. We obtained $a=b$ lattice parameters as 0.5498 , 0.5480 , and $0.5493 \mathrm{~nm}$ and $c$-axis lattice parameters as 2.4876, 2.4876, and $2.4918 \mathrm{~nm}$ for no plasma, -700 and $-350 \mathrm{~V}$ plasma, respectively.

Effects of plasma on the microstructure of pulsed laser deposited SBT films is equally significant and is generally supportive of the inferences drawn from ferroelectric and $\mathrm{x}$-ray diffraction (XRD) studies. Figure 4 shows the surface morphology of SBT films as revealed by atomic force microscopy (AFM) using a tapping mode with amplitude modulation over a scanned area of $1 \times 1 \mu \mathrm{m}$. Films grown without the plasma, having a preferred $(00 l)$, orientation display well formed large bilayered structure flat platelet grains of average size between 130 and $170 \mathrm{~nm}$. These grains are loosely packed and show voids in the intergrain regions. The large grains appear to have superimposed small flat grains. These could be the crystallites developing into larger platelets in a two-dimensional growth mode as suggested by the staircase-like growth steps. The morphology of SBT films grown in $\mathrm{O}_{2}$ plasma is quite different. It shows crystallites are semirectangular grains which appear as standing blocks of smaller average size of $\sim 90 \mathrm{~nm}$. The surface morphology is very uniform, without cracks or defects and has no inclusion of small size grains as observed in films grown without plasma. The different aspect ratios of crystallites in the two cases is in accordance with the inference drawn from XRD analysis. (a)

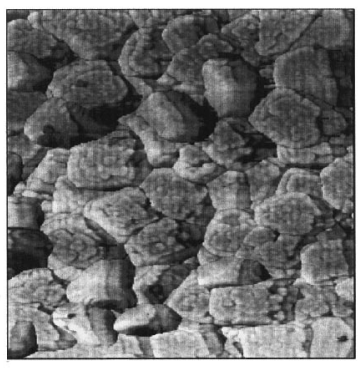

(b)

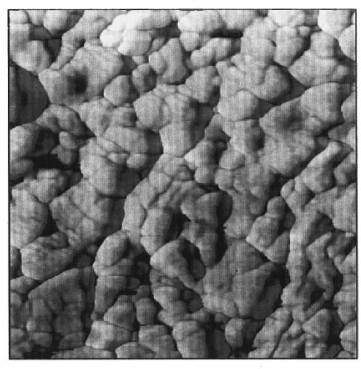

FIG. 4. AFM micrographs of PLD grown $\mathrm{SrBi}_{2} \mathrm{Ta}_{2} \mathrm{O}_{9}$ thin films in the as-deposited state (a) formed without $\mathrm{O}_{2}$ plasma and (b) formed with $\mathrm{O}_{2}$ plasma using a $-350 \mathrm{~V}$ excitation potential

In conclusion, pulsed laser deposition of SBT films in the presence of $\mathrm{O}_{2}$ plasma enables growth at a lower temperature of $700{ }^{\circ} \mathrm{C}$ and eliminates the need for any long term postgrowth crystallization step. Crystallite microstructure is highly compact, with an average grain size of $\sim 90 \mathrm{~nm}$. The crystallite orientation changes from a preferred $c$-axis normal to film plane to near parallel to the film plane. In this orientation, the perovskite stacks are arranged across the film surface with $\left(\mathrm{Bi}_{2} \mathrm{O}_{2}\right)^{2+}$ sheets at near normal to the film plane. The SBT films grown in $\mathrm{O}_{2}$ plasma show high remnant polarization $\sim 6.5 \mu \mathrm{C} / \mathrm{cm}^{2}$.

The authors would like to thank Sharp Microelectronics, I.C. Group for sponsoring the research project. One of the authors (A.C.R.) also thanks the Council of Scientific and Industrial Research, Government of India.

${ }^{1}$ C. A.-Paz de Araujo, J. D. Cuchlaro, L. D. McMillan, M. C. Scott, and J. F. Scott, Nature (London) 347, 627 (1995).

${ }^{2}$ R. Dat, J. K. Lee, O. Auciello, and A. I. Kingon, Appl. Phys. Lett. 67, 572 (1995).

${ }^{3}$ K. Amanuma and T. Kunio, Integr. Ferroelectr. 16, 175 (1997).

${ }^{4}$ S. B. Desu and D. P. Vijay, Mater. Sci. Eng., B 32, 75 (1995).

${ }^{5}$ T. Li, Y. D. Zhu, S. B. Desu, C. H. Peng, and M. Nagata, Appl. Phys. Lett. 68, 616 (1996).

${ }^{6}$ S. B. Desu, P. C. Joshi, X. Zhang, and S. O. Ryu, Appl. Phys. Lett. 71, 1041 (1997).

${ }^{7}$ P. C. Joshi, S. O. Ryu, S. Tirumala, and S. B. Desu, Mater. Res. Soc. Symp. Proc. 493, 215 (1998).

${ }^{8}$ B. C. Hendrix, F. Hintermaier, D. A. Desrochers, J. F. Roeder, G. Bhandari, M. Chappuis, T. H. Baum, P. C. Van Buskirk, C. Dehm, E. Fritsch, N. Nagel, W. Honleium, and C. Mazure, Mater. Res. Soc. Symp. Proc. 493, 225 (1998).

${ }^{9}$ M. Ichinose and M. Watanabe, Jpn. J. Appl. Phys., Part 1 36, 5893 (1997).

${ }^{10}$ D. T. Thomas, N. Fujimura, S. K. Streiffer, O. Auciello, and A. J. Kingon, Proceedings of 10th IEEE International Symposium on Applications of Ferroelectrics (1996), Vol. 1, p. 495.

${ }^{11}$ H. M. Yang, J. S. Luo, and W. T. Lin, J. Mater. Res. 12, 1145 (1997).

${ }^{12}$ Y. Oishi, Y. Matsumuro, and M. Okuyama, Jpn. J. Appl. Phys., Part 1 36, 5896 (1997).

${ }^{13}$ M. Nagata, D. P. Vijay, X. Zhang, and S. B. Desu, Phys. Status Solidi B 157, 75 (1996).

${ }^{14}$ T. Hayashi, T. Hara, and H. Takahasi, Jpn. J. Appl. Phys., Part 1 36, 5900 (1997).

${ }^{15}$ P. C. Joshi, S. O. Ryu, X. Zhang, and S. B. Desu, Appl. Phys. Lett. 70, 1080 (1997).

${ }^{16}$ T. Noguchi, T. Hase, and Y. Miyaska, Jpn. J. Appl. Phys., Part 1 35, 4900 (1996).

${ }^{17}$ E. C. Subbarao, J. Phys. Chem. Solids 23, 655 (1962).

${ }^{18}$ S. Y. Chen, X.-F. Du, and I.-W. Chen, Mater. Res. Soc. Symp. Proc. 361, 15 (1995).

${ }^{19}$ Y. Ito, M. Ushikubo, S. Yohoyama, H Matsunaga, T. Atsuki, T. Yonezawa, and K. Ogi, Jpn. J. Appl. Phys., Part 1 35, 4925 (1996). 